\title{
Rule Based Expert System Application for Crime against Women Law in Indian judicial system
}

\author{
Prof. J.S. Jadhav ${ }^{1}$, Dr. K.M. Nalawade ${ }^{2}$, Dr. M.M. Bapat ${ }^{3}$. \\ ${ }^{I}$ Asstt. Prof. S.G.M. College, Karad, Dist. Satara Maharashtra, India ,ranjitdrainak@gmail.com. \\ 2 "Principal Rajarshi Chatrapati Shahu College" Kolhapur, Dist. Kolhapur, Maharashtra, India \\ ${ }^{3}$ Principal N.S. Law College Sangali, Dist Sangali Maharashtra, India.
}

\begin{abstract}
Law is a general rule every human being is presumed to intend his acts and this presumption of lawprevails from consideration of all the evidence. This law can be considered as a set of rules (IF - THEN type) producing a knowledge base. Expert System or knowledge based system take knowledge from this knowledge base, in the form of rules, fact, heuristics and semantic net and procedures. The expertise knowledge is stored in the knowledge base. The inference engine processes this knowledge, and makes decisions only if the rule is matched with input data. In this article, the authors give study of research aspects of legal knowledge, reasoning strategies in different areas in legal domain.
\end{abstract}

Keywords: Expert system,Expertise, inference Engine, ,Knowledge Based System.

\section{Introduction}

According to Feigenbaum "An expert system is an intelligent computer program that uses knowledge and inference procedures to solve problems that are difficult enough to require significant expertise" [20]

Expert system should solve very difficult problems as well as better problems solved than human experts. They do not make use of algorithms in their main task. But they use what are the essentially rules, usually in a very domain specific. They process information in symbolic form. The rules (IF-THEN type)are used for this processing. The knowledge is accessed in the form of the rule.

Especially expert system's aim is to provide advice and suggestions to the user.

\section{1) Statement of the Problem:}

To take survey of research work on expert systems in legal domain and its application.

\section{2) Purpose}

The purpose of the study is to undertake survey, in brief, of the other research work in the area of legal knowledge based system.

\section{3) Significance of the study}

It is difficult to develop a system which has the intellectual process of a human being as legal expert. It is possible to understand and create a computer logic in law. Hence we feel that the study taken to know about the research done in the area of legal expert system. This will help the authors in their research of creating new prototype of an expert system in one of the aspect of legal system with special reference to crime against women.

\section{Connection In Ai And Law}

In artificial intelligence, an expert system is a computer system that has decision making ability like a human expert. Expert system is a branch of artificial intelligence. Expert system are designed to solve complicated problems by reasoning about knowledge [1] [20]. Hence it is used to solve legal problem for decision making.

\section{1) Expert System and Law}

Expert system has been also called as white collar robots. They are simple minded domain specific [20]. An expert system which give advice on the law to the user's specific legal problem. These are called as "legal Expert System" but it is commonly called as "computerized legal Advisory Systems." At present, there is a lot of interest in the development of legal expert system.

Development of legal expert system is second ware or inning of artificial intelligence. The purpose of a developing Knowledge Based System is not only to provide solutions to legal problems but also to incorporate legal knowledge and reasoning strategies into the automation of legal tasks. It will be used when experts AI 
techniques is used to create. 'Automated Legal Reasoning Systems.' Computer systems that reasons with and apply the law to solve problems.

\section{2) Application of Legal Expert System}

The authors during the study of related literature observed that since 1989, there has been a special trend of using the expert system: They were used for-

1. Computer applications implementing AI concept.

2. Organizational systems to knowledge acquisition storage and retrieval of knowledge.

Most of studies carries out with references to expert system. In study of literature of survey of legal expert system developed can be of following types [12] [ from reviewing different article]

1. Expert system and main computerized model inference

2. Expert system and main formal advisory systems.

3. Automatic document generators expert systems.

4. Legal theory and computerization.

5. Conceptual information retrieval system.

6. Theory construction, evaluation and application systems.

7. Law on legal argument and AI

8. Automated legal document systems.

9. Web based legal inferencing system.

10. Transaction support system.

11. Intelligent retrieval systems

12. Case based reasoning systems.

In the subsequent part, the authors give the study conducted by many authors who have given the view points on the aspect of the study which is topic of the paper.

Henry Prakken et al [13] opine that arguments found in the case files and judicial decisions can be complicated. Computer is having potential to provide a means of addressing this problem i.e. argument structuring systems. He designed a tool 'Avers' for crime analysis that supports reasoning for formulating argumentation for linking evidence. The authors present the evaluation system by Alan Tyree [2] and he developed the expert system named 'FINDER' used to solve limited class of legal problems. It was written in Basic FINDER is used as information retrieval system. It is also a possibility that the use of expert systems in the teaching of law, because FINDER knows so much about the law.

Bench Capon et al [4] proposed the reasoning with legal cases. They proposed a set of theory constructors to specify the process of theory construction. The authors also discuss previous work done in this area. The authors come out with some proposals for legal theory. Lees Groendijk and Maaike Tragter [10] developed legal expert system to support police officers with the task of enforcing the legislation. It takes many design decisions. Demulder et al [11] in 1994, developed a expert system containing very large collection of legal cases and formal legislation and techniques. He named the system 'Learning Concept Processor' which enables user to define his own concepts and enter into these system.

The authors provide an example of a model based legal reasoning. This model based legal reasoning system is proposed by Haan and Breuker et al [21] by concerning inferential explosions in the proof procedures in legal systems. The proof procedure resolves the navigation problem that emerges in traffic law research. They develop prototype named as Traffic Regulation Animation and Comparison System. The AI researchers added specializing in law of new AI techniques like model based, web based case based reasoning, fuzzy logic, and neural networks but unfortunately there occurred some drawbacks that need to be overcomes. Thomas Gordon [24] developed the argument construction set legal expert system. The law can be represented as set of rules and used for legal decision making. He constructs expert system which assists. Lawyers with legal reasoning. The authors provide the logic of reasonable inferences. It is model for justification of legal decisions. It was developed by Mestdagh, Verwaqrd, Hoepman [7]. But it is somewhat inconsistent because of allowing derivation of conflicting conclusions.

Groendijk and Maaike Tragter [10] developed legal knowledge based system to support police officers with the task of enforcing penal environmental legislation. They developed a model into forensic science lab (FSL) in which analysis and investigations of evidence for criminal cases. Groendijk and tragter gave name to model 'MILIEV' which describes how police officer should investigate appropriately. The authorsdiscusses in this article the relation between legal knowledge based systems and legal theory given by bench capon [25]. He discussed in article that legal knowledge based systems are built by computer scientists. Legal theory can be used to analyze them this analysis may emerge the jurisprudent which is feasible and clear. Trevor bench capon [26] used argument in $\mathrm{AI}$ and law.

Jaap Diskstra [15] summarized in user interaction with legal knowledge based systems that they construct a small, transparent legal knowledge based system to help lawyers with routine decision making. 
Improving the user friendliness of LKBS is not enough when users are not motivated to supervise the system and reduce their own cognitive efforts. It should be conceptualized as instrument tool that supports effective performance. For example ELM and TAM examine the interaction between users and LKBS.

Cary Debessonet [8] studied the automated intelligent system based on a model of legal system. This model is CCLIPS i.e. Civil Code Legal Information Processing System. The system uses artificial intelligence techniques to generate intelligent responses to input. The authors presented a study of model based computer system for teaching legal case solving. The study was carried out byMuntjewerff and Winkels [16]. They developed a system 'ROSA' which provides a solution for problems experienced by law students when solving legal cases. They propose a computer coach for training legal case solving in the form of ROSA system. The ROSA is teachable, explicit and learnable model of legal case solving; executable by machines and by humans. In the study of Constitutional Law and AI the potential legal recognition of computers as persons created by Marshal Willick [17] concluded that constitutional law will recognize at least some computer system as 'persons' because they are behave exhibiting, consciousness, understanding and learning. The authors discussed knowledge based system prototype application for transfer of property law in Indian Judicial System Studied by N.B. Bilgi and R.V. Kulkarni [22]. They developed a comprehensive rule based system for transfer of property which can act as great too, for experts in the field of law.

In recent years ,practical applications of legal knowledge based systems have become increasingly common in public administration, persecution assistance, legal advice, and e-government. This raises the issue of quality of actual functioning in practice [18]. Henry Prakken et al [13] concluded in their study of AI and law on legal argument research trends end application prospects that research on legal argument is to embedded natural and Flexible representation of legal arguments in formal and rigorous models of legal argument. Marga groohuis and svensson [19] gain in their study of expert system support and juridical quality that expert system is becoming more popular for problem of juridically correct decision making. AI now operates as a kind of advanced version of LEXIS offering research assistance rather than analogical reasoning. This summarized by Cass Sunstein [9] in public law and legal theory of AI and legal reasoning.

\section{3) Terms used-Different terms used in this study. They are-}

\subsection{1) Expert Systems-}

The term Expert system and knowledge based system is interchangeably means as sums that readers are familiar with the main concepts of expert system. The Wikipedia gives definition of expert system as "It is software that attempts to provide an answer to a problem or clarify uncertainties where normally one or more human experts to be consulted. A system is designed for solving the problems in a specific application area. One can draw an inference from a stored knowledge base that was developed by recording and structuring human expertise through oan individual called as knowledge engineer. (www.agriculture.purdue.edu/ssmc/frames/newglossary.htm)

The number of definition of expert in systems are cited in the literature. The expert system is computer program that helps to solve problems or make decisions through the use of a store of relevant information i.e. knowledge base derived from one or more human experts and a set of reasoning techniques [wwwmarkintell.com/language.business.intelligence).

Different expert system shells are used. They represent knowledge. There are two types of knowledge representation rule based and frame based. Developing expert system is known as knowledge engineering and the individual who encodes the experts knowledge in a declarative form that can be used by the expert system.

In short expert system operates an interactive system that responds or answers to questions asks for clarifications and make decisions making process [3]

This means-

1. Expert system responds to questions.

2. It asks for clarifications.

3. It makes recommendations.

4. It aids decision making process.

\section{Result}

The authors of this paper opine that judicial laws have been codified in expert system. Theforms of expert system are - case based reasoning, automated legal reasoning and rule based reasoning. The result of this study is that from two decades expert system is used in legal system in its sub domainapplication area like crime analysis ,criminal searching, decision making, crime reporting, law related problem investigation etc. 


\section{Conclusion}

It is effective and advantageous to codify the law in the form of rulesby using expert system. This is also the opinion of other authors of other papers which are cited in the review literature study. The authors of this paper concluded that rule based expert system have been used in judiciary domain in India.

Hence the authors have undertaken a research work in judiciary domain of rule based expert system with special reference to crimes against women. The study reveals that this legal expert system is useful to Indian women to make legal decision independently. The research work is in developing stage of prototype of Rule Based Expert system for one of the aspect of Indian legal domain system with special reference to crimes against women in satara district. The implementation of expert system will be done in an expert system shell in VB.net.

\section{References}

[1]. A Tyree Expert systems in law prentice hall (Aust) 1989

[2]. Alan 2 Tyree, "FINDER" an expert system. Globe pharma GPHF,minilabmanuals.http, www.gphf.org/web/en/minilab/manual.htm

[3]. A Practical Introduction to Rule Based Expert Systems ,M. Sasikumar S. Ramani.

[4]. Bench capon, "Theory Construction."

[5]. Less Groendijk, Maaike Tragter I "Legal Theory and Design of MILIEV"

[6]. C.A.M. wildemast and R.V. Demulder- "Some design considerations for a conceptual legal Information Retrival system in: Legal knowledge Based systems JURIX 92: Information Technology \& law pp.81-92,1994, ISBN 9054580313

[7]. CNJ De vey mestdagh ,W. verwaqrd J.H. Hoepman; “The Logic of Responable Inferences In Legal Knowledge based legal reasoning pp; 60-76, 1991, ISBN: 9060409892.

[8]. Carry Debessonet, Automated Intelligent System Based on a Model of Legal System in: Rutgers computers and technology law journal 1983-84.

[9]. Cass R Sunstein, "Public law and legal Theory working of Artificial Intelligence and Legal Reasoning, Paper No. - 18 http://papers.ssrh.com/paper.tatqabstract id=289789.

[10]. Less Groendijk, Maaike Tragter , Legal Theory and Design of MILIEV" computer/law institute, vrije Universite Amsterdam, The Netherlands.

[11]. C.A.M. wildemast and R.V. Demulder- "Some design considerations for a conceptual legal Information Retrival system in: Legal knowledge Based systems JURIX 92: Information Technology \& law pp. 81-92, 94 ISBN- 9054580313.

[12]. Graham Gneenfeat, "Legal Expert Systems 'ROBOT' Lawyers? An Introducition to knowledge based application to law "presented at Australian legal convention, Darling, harbous, Sydney, August 89.

[13]. Henry Prakken "AI and law on legal Argument: ResearchTrends and Application Prospects.

[14]. In Addition to journal articles reference may made to R. Suskind Expert Systems in law clarenden press Oxford 1987 A VDL Gardiner An artificial Intellegence approach to legal Reasoning MIT press, 1988.

[15]. JAAP Dijkstra "User Interaction with legal knowledge based systems" in legal knowledge and information system Jurix 2000. The Thirteenth Annual Conference, Amsterdam, 2000 PP: 11-21.

[16]. Muntje werff and Winkels ROSA - A model based computer System for teaching legal case solving in legal knowledge based systems, jurix 95, 133-141, ISBN: 9054582529.

[17]. Marshal Willick; Paper Constitutional Law and Artificial Intelligence: The Potential Legal Recognition of Computers as "Persons".

[18]. Michael Aikenhead, Legal Knowledge Based Systems: Some Observations on the future in; web journal of current legal Issues, 1995, P9 1-9 W.

[19]. Marga M Groothuis, Jorgen S Svensson, Expert System Supper and juridical quality in: Legal Knowledge and Information Systems, Jurix 2000. The thirteenth Annual Conferences, Amsterdam IOS Press, 2000, PP1 -10.

[20]. M. Sasikumar, s. Ramani S. Muthu Raman, KSR Anjaneyulu R ousehnadrasekar, "a practical intruduction to rule based expert systems" by Narosa Publishing House New Delhi, 2007.

[21]. Nienke den Haan and joost Breuker, "A Tractable Juridical KBS for Applying and teaching traffic Regulations (Jurix 91) model based legal reasoning, PP 5-16,1991, ISBN 9060409892.

[22]. N.B. Bilgi, R.V. Kulkarni.

[23]. Dr. Priyanka Sharma, CHallegen and current Trends in Knowledge based System in International Journal Technology E-ISBN 0976-3945.

[24]. Thomas F Gordan, "The argument Construction set- A Constructive Approach to legal Expert systems.

[25]. Trevor Bench Capon - Legal Theory and legal KBS: A Computer Scientists Perspective. In Legal Knowledge based systems, JURIX 94, PP - 33-42. ISBN 9054581905.

[26]. Trevor bench capon "Argument in Artificial Intelligence and Law" in legal knowledge based system, JURIX 95, 5-14, ISBN 9054582529.

[27]. www.jurix.utwente.in 